\title{
MODIFICAÇÃO QUÍMICA DE ARGILAS: DESAFIOS CIENTÍFICOS E TECNOLÓGICOS PARA OBTENÇÃO DE NOVOS PRODUTOS COM MAIOR VALOR AGREGADO
}

\author{
Érico Teixeira-Neto* e Ângela Albuquerque Teixeira-Neto \\ Centro de Ciências Naturais e Humanas, Universidade Federal do ABC, Rua Santa Adélia, 166, 09210-170 Santo André - SP, Brasil
}

Recebido em 15/1/09; aceito em 19/3/09; publicado na web em 2/4/09

\begin{abstract}
CHEMICAL MODIFICATION OF CLAYS: SCIENTIFIC AND TECHNOLOGICAL CHALLENGES FOR OBTAINING NEW VALUE-ADDED PRODUCTS. Chemical modification of clays is possible due to their ion-exchange and adsorption capacities, which allows the adjustment of the physicochemical properties of the surfaces of their layers. This modification makes possible the use of clays to produce a great number of new materials, which range from coarse applications such as oil based drilling fluids to refined applications such as pharmaceutical products. This article intends to expose where there is still space for research and investment aiming at the performance improvement of clay-based materials.
\end{abstract}

Keywords: bentonite; pillared clays; controlled release.

\begin{abstract}
"Não se tira nada de nada, o novo vem do antigo, mas nem por isso é menos novo."
\end{abstract}

Bertolt Brecht, 1898 - 1956 (dramaturgo, poeta e encenador alemão)

\section{INTRODUÇÃO}

Argilas têm sido usadas pela humanidade desde a antiguidade para a fabricação de objetos cerâmicos, como tijolos e telhas e, mais recentemente, em diversas aplicações tecnológicas. As argilas são usadas como adsorventes em processos de clareamento na indústria têxtil e de alimentos, em processos de remediação de solos e em aterros sanitários. São usadas para ajustar as propriedades reológicas de fluidos de perfuração de petróleo e de tintas, como carreadoras de moléculas orgânicas em cosméticos e fármacos e como suporte para catalisadores. $\mathrm{O}$ interesse em seu uso vem ganhando força devido à busca por materiais que não agridem o meio ambiente quando descartados, à abundância das reservas mundiais e ao seu baixo preço. ${ }^{1}$ A possibilidade de modificação química das argilas permite o desenvolvimento do seu uso para diversos tipos de aplicações tecnológicas, agregando valor a esse abundante recurso natural.

Um levantamento recente do número de patentes e de trabalhos acadêmicos contendo as palavras argila e argilas ou clay e clays, realizado nas bases de dados Web of Science $^{\circledR}$, Espacenet $\mathrm{e}$ INPI pode ser visto na Tabela 1. A análise dos resultados mostra que os pesquisadores acadêmicos brasileiros contribuem com fração relevante $(3,6 \%)$ dos trabalhos publicados internacionalmente sobre argilas. Essa fração é maior do que a fração total de trabalhos acadêmicos brasileiros frente à produção mundial, que segundo a CAPES foi de 2,0\% em 2007. ${ }^{2}$ Entretanto, a fração brasileira de registros de patentes protegendo a fabricação de produtos que usam argilas é de apenas $0,4 \%$. Considerando que a maior parte desses registros foi feito por indústrias estrangeiras e que o Brasil é responsável por $2,0 \%$ da produção mundial de argilas, a participação das indústrias e universidades nacionais na proteção de tecnologias para aplicação de argilas em produtos é muito baixa.

*e-mail: erico.teixeira@ufabc.edu.br
Tabela 1. Levantamento do número de patentes e de trabalhos envolvendo o uso de argilas nas bases de dados indicadas

\begin{tabular}{cccc}
\hline Base de Dados & Palavras-chaves & Patentes & \\
\hline Espacenet & clay ou clays & 50.997 & \\
INPI & argila ou argilas & $222(0,4 \%)$ & \\
\hline Base de Dados & Palavras-chaves & Artigos & Revisões \\
\hline Web of Science & clay ou clays & 50.171 & 2.401 \\
& clay ou clays, & $1.808(3,6 \%)$ & $15(0,6 \%)$ \\
& Brazil & & \\
\hline
\end{tabular}

\section{RECURSO NATURAL: ARGILAS}

As argilas são comumente definidas como materiais naturais, terrosos, de granulação fina que, quando umedecidos com água, apresentam plasticidade. De modo geral, o termo argilas refere-se às partículas do solo que possuem diâmetro inferior a $2 \mu \mathrm{m}$ e das quais podem fazer parte diferentes tipos de minerais: silicatos lamelares de magnésio e de alumínio (filossilicatos), quartzo, feldspato, carbonatos, óxidos metálicos e até mesmo matéria orgânica. $\mathrm{O}$ termo argilominerais é usado para designar especificamente os filossilicatos, ${ }^{1,3}$ que são hidrofílicos e conferem a propriedade de plasticidade às argilas. O total de componentes que não são argilominerais nas argilas dificilmente é inferior a $10 \%$ em massa. ${ }^{4}$ Não há uniformidade no uso dos termos argilas e argilominerais na literatura científica e, portanto, nesse texto eles serão usados de forma intercambiável.

Na Figura 1 são mostrados difratogramas de raios $\mathrm{X}$ de uma amostra de argila, denominada argila $\mathrm{K}$, in natura (bruta) e após fracionamento por peneiramento com corte granulométrico de $2 \mu \mathrm{m} .{ }^{5}$ A atribuição dos picos nos difratogramas mostra que a argila bruta é formada por minerais do grupo das esmectitas (E) contendo impurezas, como quartzo (Q) e feldspato (F). Grande parte das impurezas, como quartzo e feldspato, pode ser removida com um corte granulométrico abaixo de $2 \mu \mathrm{m}$, como pode ser observado pela variação nas intensidades relativas dos picos E, Q e F na Figura 1, obtendo-se uma amostra rica no argilomineral do grupo das esmectitas.

Uma descrição detalhada da estrutura cristalina dos filossilicatos pode ser encontrada em livros e em revisões. ${ }^{1,3,6}$ Resumidamente, 


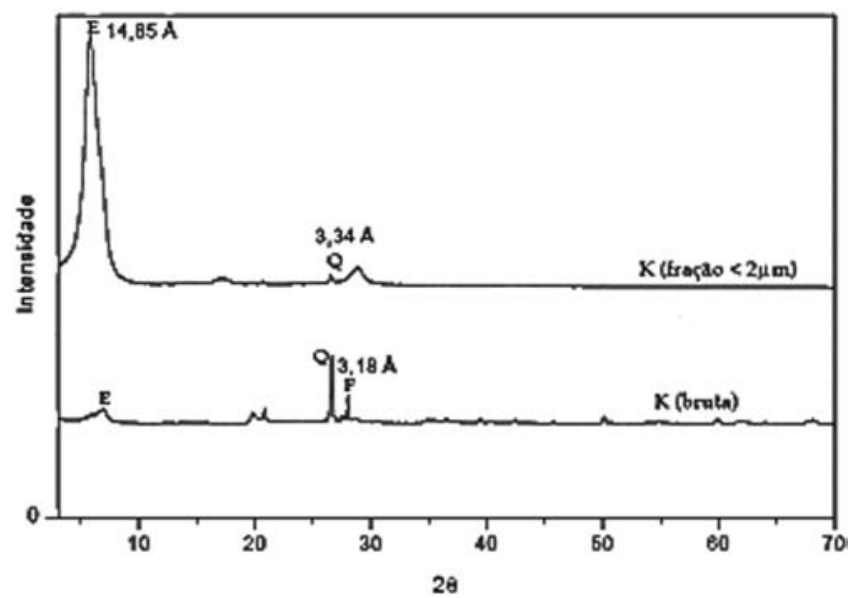

Figura 1. Difratogramas de raios $X$ de amostras da argila $K$ in natura e da fração $<2 \mu m$ após peneiramento. $(E=$ esmectita, $Q=$ quartzo, $F=$ feldspato). Adaptada da ref. 5

as argilas possuem uma estrutura formada por lamelas cristalinas nanométricas quasi bidimensionais empilhadas, como um baralho de cartas. As lamelas têm pouco menos que $1 \mathrm{~nm}$ de espessura e poucas centenas de nanômetros de diâmetro médio. Cada lamela é formada pelo arranjo de dois tipos de folhas cristalinas, com estrutura octaédrica ou tetraédrica. Os diferentes grupos de argilas são definidos de acordo com a maneira com que as folhas tetraédricas e octaédricas se arranjam, formando as lamelas: 1:1 - na qual apenas uma folha tetraédrica está ligada a uma folha octaédrica; e 2:1 - na qual uma folha octaédrica está ensanduichada no meio de duas folhas tetraédricas. ${ }^{6} \mathrm{O}$ tipo mais comum e abundante de argila é a caulinita, 1:1. Entre as argilas 2:1, a montmorilonita figura entre as mais abundantes e tecnologicamente relevantes.

As folhas tetraédricas são formadas por tetraedros de $\mathrm{Si}-\mathrm{O}$ com cantos compartilhados, como mostrado no digrama esquemático da Figura 2a. ${ }^{7}$ Cada tetraedro compartilha três de seus cantos com três tetraedros vizinhos, resultando em uma fórmula estrutural de $\left(\mathrm{Si}_{2} \mathrm{O}_{5}\right)$ ${ }_{n}$ para a folha. Da mesma forma, as folhas octaédricas são compostas por cátions $\mathrm{Al}^{3+}$ ligados a ânions $\mathrm{O}^{2-} \mathrm{e} \mathrm{OH}^{-}$, resultando em uma fórmula química efetiva de $\mathrm{AlO}(\mathrm{OH})_{2}$. A estrutura dessa camada é mostrada na Figura $2 b$.
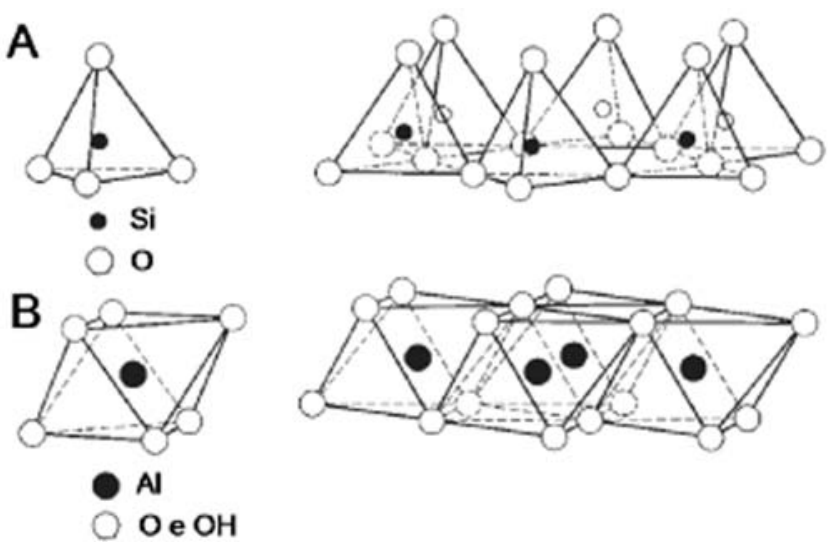

Figura 2. Diagrama esquemático de uma folha tetraédrica (a) e de uma folha octaédrica $(b)$

A ligação entre as folhas cristalinas octaédricas e tetraédricas é feita quando cada tetraedro $\mathrm{Si}-\mathrm{O}$ na folha tetraédrica compartilha um oxigênio com um octaedro $\mathrm{Al}-\mathrm{O} / \mathrm{OH}$ da folha octaédrica, na representação esquemática em perspectiva da estrutura cristalina da montmorilonita da Figura $3{ }^{8}$ As ligações químicas entre os átomos dentro de cada folha que formam as lamelas são fortes, do tipo covalente. Em contraste, as ligações entre as lamelas adjacentes são relativamente fracas, permitindo a separação das lamelas quando colocadas em excesso de água ou sob tensão mecânica.

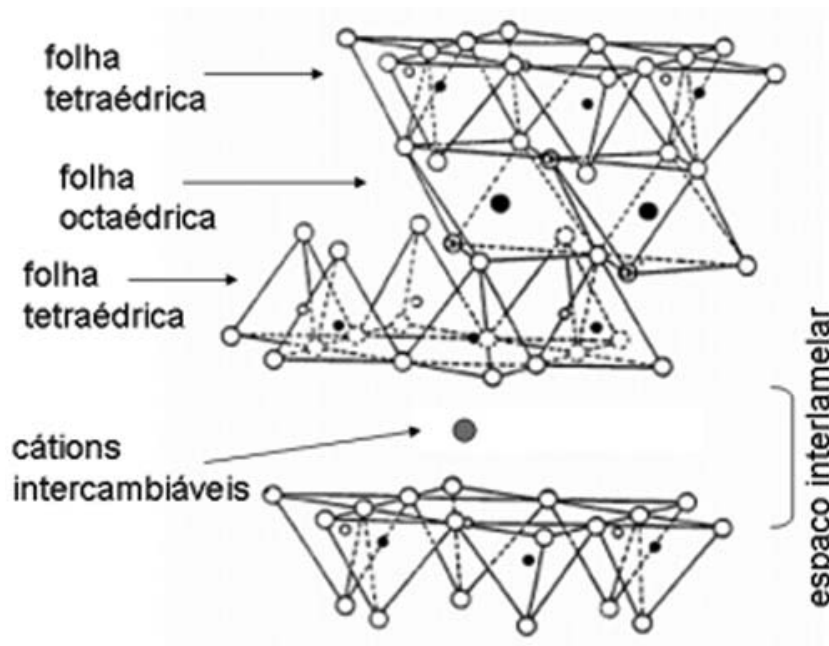

Figura 3. Diagrama esquemático geral de argilas do tipo esmectita. Adaptada da ref. 8

Algumas argilas do tipo 2:1, como a montmorilonita, possuem deficiência de cargas positivas em sua estrutura cristalina, causada por substituições isomórficas, resultando em um excesso de cargas negativas distribuídas pela superfície das lamelas. Estas substituições podem ser do $\mathrm{Si}^{4+}$ pelo $\mathrm{Al}^{3+}$ nos sítios tetraédricos, do $\mathrm{Al}^{3+}$ pelo $\mathrm{Mg}^{2+}$ ou do $\mathrm{Mg}^{2+}$ pelo $\mathrm{Li}^{+}$(ou uma vacância) nos sítios octaédricos. $\mathrm{O}$ excesso de cargas negativas resultante é contrabalanceado por cátions interlamelares hidratados alcalinos, $\mathrm{Na}^{+}, \mathrm{K}^{+}$, ou alcalinos terrosos $\mathrm{Ca}^{2+} \mathrm{e} \mathrm{Mg}^{2+}$, como representado no diagrama esquemático da Figura $3{ }^{8}$

As argilas do grupo das esmectitas, do qual a montmorilonita faz parte, exibem uma alta capacidade de troca de cátions. Isto é, os cátions dentro das lamelas cristalinas e, principalmente, os cátions interlamelares podem ser trocados por outros cátions presentes em uma solução aquosa sem que isso modifique a estrutura cristalina das argilas. A capacidade de troca catiônica é uma propriedade importante das argilas, pois pela troca de cátions pode-se modificá-las quimicamente influindo diretamente sobre suas propriedades físicoquímicas e possíveis aplicações tecnológicas. Os cátions trocáveis podem ser orgânicos ou inorgânicos. Adicionalmente, a hidratação dos cátions interlamelares causa o acúmulo de moléculas de água no espaço interlamelar das argilas e seu consequente inchamento ou expansão, ${ }^{6}$ aumentando as distâncias interlamelares.

O foco desse artigo será a modificação química de argilas do grupo das esmectitas, por troca de cátions inorgânicos e orgânicos ou adsorção de moléculas orgânicas dentro dos espaços entre as lamelas do mineral. Não abordaremos as argilas catiônicas sintéticas, bem como os hidróxidos duplos lamelares, que são geralmente classificados como argilas aniônicas. 


\section{DEPÓSITOS DE ARGILA E EXPLORAÇÃO DO MINERAL}

Em um depósito de argila, a natureza da mistura de minerais e a composição dos minerais argilosos individuais podem variar radicalmente em uma extensão de poucos centímetros. ${ }^{9}$ Consequentemente, qualquer depósito pode conter muitos tipos de argila sutilmente diferentes. Resultados de análises químicas e mineralógicas de amostras de argilas realizadas em laboratórios diferentes podem não ser sempre comparáveis porque elas podem não conter misturas idênticas de argilominerais. Tal confusão dificulta a determinação das características desse importante grupo de materiais.

É muito comum o uso do termo bentonita para designar o mineral constituído principalmente pela montmorilonita ou por materiais com alto teor de esmectitas. ${ }^{10}$ Para uso industrial, existem dois tipos de argilas bentoníticas: as que não incham em presença de água, que têm o cálcio como cátion interlamelar predominante, e as que incham em presença de água, nas quais o sódio é o cátion interlamelar predominante. As bentonitas sódicas adsorvem água continuamente inchando e aumentando de volume até a completa esfoliação de suas lamelas cristalinas em água, proporcionando à bentonita sódica os seus usos tecnológicos característicos e exclusivos. As bentonitas cálcicas não se esfoliam em suspensão aquosa: o inchamento de suas partículas é pequeno e elas precipitam rapidamente. As bentonitas produzidas no Brasil são cálcicas e o país não tem reservas de bentonitas sódicas. Toda bentonita sódica disponível no país ou é importada ou é produzida a partir da bentonita cálcica, em um processo de beneficiamento (ativação), usando carbonato de sódio. ${ }^{11}$

Geologicamente, as bentonitas foram formadas a partir de cinzas ou rochas vulcânicas. ${ }^{7}$ Segundo o Departamento Nacional de Produção Mineral, o Brasil é responsável por $2 \%$ da produção mundial de bentonita. ${ }^{10}$ Os Estados Unidos são os maiores produtores de bentonita no mundo, sendo responsáveis por mais de $43 \%$ da produção mundial, seguido pela Grécia $(9,4 \%)$ e pela Turquia $(8,5 \%)$. As maiores reservas mundiais localizam-se nos Estados Unidos, no estado de Wyoming. As maiores reservas brasileiras estão localizadas nos estados da Paraíba e do Paraná, com respectivamente 55 e $24 \%$ do total disponível.

Em 2007, a produção estimada de bentonita bruta no Brasil atingiu 329.647 t. O estado da Paraíba produziu $88,5 \%$ de toda a bentonita bruta brasileira, seguido por São Paulo com 7,3\%, Bahia com 3,9\%, e Paraná, com apenas $0,2 \%$. Oficialmente, 14 empresas exploram argilas bentonitas no país. No ano de 2007 houve uma diminuição de $21 \%$ na produção de bentonita bruta no Brasil em relação a 2006 , resultado da paralisação da lavra, por razões técnicas e econômicas, de 2 empresas localizadas em Boa Vista/PB. ${ }^{10}$

Os dados preliminares relativos ao consumo estimado de bentonita bruta no Brasil, no ano de 2007, indicaram a seguinte distribuição de aplicações: extração de petróleo/gás (54\%) e pelotização (46\%). As finalidades industriais para a bentonita beneficiada (moída e seca) distribuíram-se entre graxas e lubrificantes com 78,7\%, fertilizantes com $11,1 \%$, óleos comestíveis com $7,7 \%$ e fundição com $2,4 \%$. Os usos industriais da bentonita ativada (sódica) distribuíram-se entre pelotização de minério de ferro com $63 \%$, fundição com $19,7 \%$, ração animal com $11,6 \%$, extração de petróleo e gás com 5,5\% e outros produtos químicos com $0,2 \% .^{10}$

\section{BENEFICIAMENTO DAS ARGILAS}

Cada tipo de aplicação industrial ou acadêmica de bentonitas demanda materiais com características específicas, que só podem ser atendidas pela seleção criteriosa das matérias-primas extraídas pelas indústrias mineradoras e pela sua purificação e beneficiamento adequados. Para uso como componente dos fluidos de perfuração de poços de petróleo, as bentonitas devem ser sódicas, com alto grau de inchamento, enquanto que para uso como descorante, as bentonitas preferidas são normalmente as que apresentam $\mathrm{Ca}^{2+} \mathrm{e} / \mathrm{ou} \mathrm{Mg}^{2+}$ como cátions trocáveis. ${ }^{4}$ As bentonitas portadoras tanto de $\mathrm{Na}^{+}$como de $\mathrm{Ca}^{2+}$ são adequadas à aplicação em moldes de fundição. $\mathrm{O}$ beneficiamento das bentonitas cálcicas brutas inclui algumas etapas, como ativação e fracionamento, e agrega valor ao mineral. Assim, pode-se realizar a exploração racional das jazidas nacionais e evitar o esgotamento prematuro de filões de mineral com características mais nobres, que são geralmente menos abundantes em uma jazida.

\section{Ativação}

A maior parte das aplicações industriais e acadêmicas de argilas é feita usando-se bentonitas sódicas. As bentonitas brasileiras, cálcicas, podem passar por um processo de ativação usando carbonato de sódio (barrilha) para a troca dos cátions interlamelares de $\mathrm{Ca}^{2+}$ por $\mathrm{Na}^{+}$. Esse processo de troca iônica foi desenvolvido e patenteado na Alemanha, em 1933, pela empresa Erbsloh \& Co e é atualmente utilizado pelos países que não dispõem de bentonita sódica natural. ${ }^{4} \mathrm{O}$ íon $\mathrm{Na}^{+}$ hidrata-se mais que o $\mathrm{Ca}^{2+}$. Além disso, a distância interlamelar nas bentonitas é maior quando as lamelas têm suas cargas compensadas pelo íon sódio, de menor valência, permitindo a penetração de uma maior quantidade de água no espaço entre as lamelas. Isso explica porque a capacidade de expansão da bentonita sódica é muito maior do que a do tipo cálcica.

O processo de ativação das bentonitas cálcicas brutas inclui as seguintes etapas: desintegração/moagem, adição de 2,5 a 3,0\% em peso de barrilha, homogeneização, laminação ou extrudagem (essa etapa é feita com a umidade da mistura em torno de $34 \%$ e tem a finalidade de promover maior contato da barrilha com a montmorilonita), cura e secagem em temperatura ambiente por um período entre 48 e 180 h (até a mistura atingir um nível de umidade em torno de $12 \%$ ), moagem, classificação e ensacamento. ${ }^{4}$ A Figura 4 mostra o efeito do percentual em massa de barrilha, adicionado no processo de ativação de uma amostra de bentonita, sobre sua capacidade de inchamento.

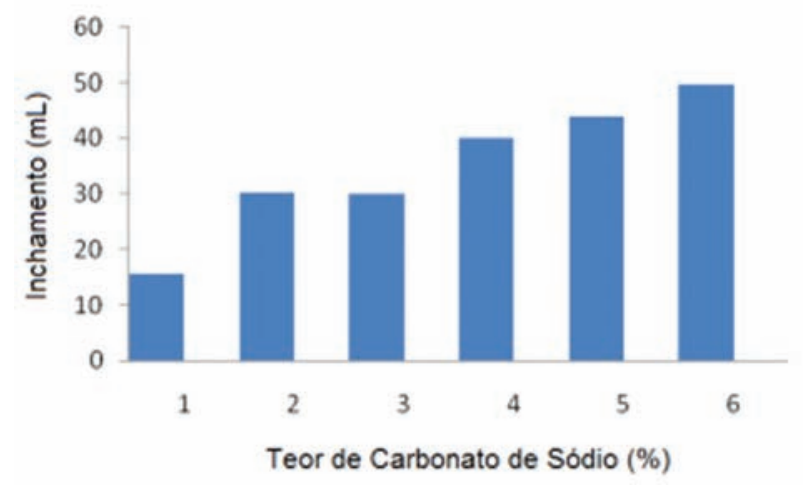

Figura 4. Efeito do teor de carbonato de sódio no inchamento da argila. Adaptada da ref. 11

\section{Ativação ácida}

Quando a bentonita se destina à aplicação em processos industriais, como catálise, ${ }^{12}$ clarificação de óleos comestíveis ${ }^{13}$ e bebidas, produção de papel e de fármacos, ${ }^{14}$ ao invés de ativação com barrilha é feita uma ativação ácida usando ácido clorídrico ou sulfúrico. As propriedades estruturais das argilas naturais são modificadas pelos métodos de ativação ácida, produzindo materiais com áreas superficiais maiores, maior acidez e porosidade, além de boa estabilidade térmica. ${ }^{15}$ 
Tais tratamentos causam a troca iônica dos cátions interlamelares $\left(\mathrm{Na}^{+}\right.$ou $\left.\mathrm{Ca}^{2+}\right)$ por $\mathrm{H}^{+}$e fazem com que cátions das lamelas cristalinas, como $\mathrm{Al}^{3+}$ das folhas octaédricas, sejam retirados das suas posições na estrutura cristalina, deixando os grupos tetraédricos $\mathrm{SiO}_{4}$ intactos. ${ }^{16}$ Esse processo geralmente aumenta a área superficial de argilas brutas em até cinco vezes, e também a sua acidez, junto com a eliminação de muitas impurezas minerais e a dissolução parcial das lamelas cristalinas. Na Figura 5 são apresentados difratogramas de raios X referentes a amostras de bentonita ativada com ácido sulfúrico em concentrações crescentes (de 10 a 70\%). Essa figura evidencia a diminuição progressiva da cristalinidade da montmorilonita, pela diminuição da intensidade relativa dos picos indicados pela letra $\mathrm{S}$, destacados em amarelo na Figura 5, causada pelo tratamento ácido. ${ }^{17}$

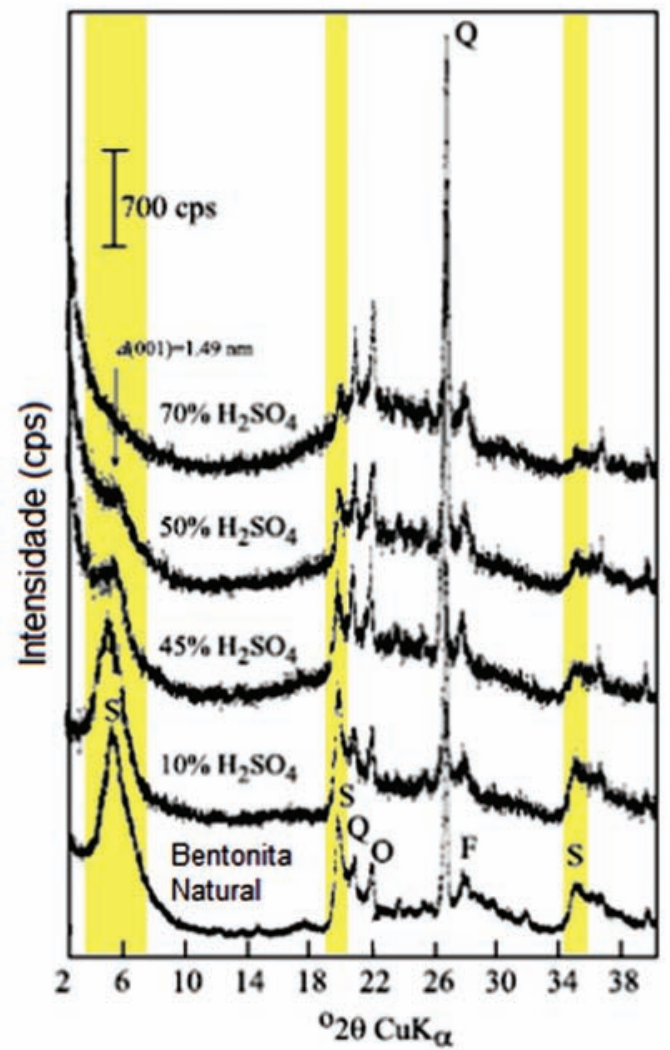

Figura 5. Difratogramas de raios $X$ de bentonita natural e de amostras ativadas com ácido ( $S=$ esmectita, $Q=$ quartzo, $O=$ opala, $F=$ feldspato $)$. Adaptada da ref. 17

Önal e Sarikaya ${ }^{17}$ observaram que há uma perda de alumínio e de ferro bastante significativa quando se aumenta a concentração do ácido sulfúrico usado no tratamento de bentonitas (Tabela 2). Observa-se que, para fins de troca iônica de $\mathrm{Ca}^{2+}$ por $\mathrm{H}^{+}$, um tratamento com $\mathrm{H}_{2} \mathrm{SO}_{4}$ a $20 \%$ já fornece um bom grau de troca, com pequena perda da cristalinidade da argila. Para aplicações em adsorção, elementos filtrantes ou em descoramento de óleos, ${ }^{8}$ por exemplo, pode ser interessante o uso de altas concentrações de ácido, que fornecem um material praticamente amorfo, mas bastante poroso. ${ }^{17}$

Desse modo, a intensidade do tratamento ácido deve ser escolhida de acordo com a aplicação do material, para que as propriedades mais importantes sejam ajustadas da melhor maneira. Em catálise, por exemplo, pode haver a necessidade de um material com alta acidez de Brønsted. O tratamento ácido moderado aumenta o número de sítios ácidos na superfície, mas um tratamento mais longo pode levar à diminuição desses sítios, devido à destruição parcial da estrutura cristalina. $^{18}$
Tabela 2. Resultados de análise química para bentonita natural e ativada com ácidos, obtidos por Önal e Sarikaya

\begin{tabular}{lccccc}
\hline$\% \mathrm{H}_{2} \mathrm{SO}_{4}$ & $\mathrm{SiO}_{2}$ & $\mathrm{Al}_{2} \mathrm{O}_{3}$ & $\mathrm{Fe}_{2} \mathrm{O}_{3}$ & $\mathrm{CaO}$ & $\mathrm{Na}_{2} \mathrm{O}$ \\
\hline 0 & 70,70 & 13,55 & 0,71 & 1,88 & 0,14 \\
10 & 72,90 & 13,45 & 0,70 & 0,93 & 0,11 \\
20 & 75,05 & 12,25 & 0,62 & 0,84 & 0,09 \\
30 & 77,05 & 10,95 & 0,51 & 0,78 & 0,07 \\
40 & 78,10 & 10,10 & 0,46 & 0,65 & 0,06 \\
50 & 79,95 & 9,40 & 0,41 & 0,59 & 0,05 \\
60 & 81,70 & 8,45 & 0,40 & 0,51 & 0,05 \\
70 & 82,05 & 7,85 & 0,38 & 0,43 & 0,04 \\
\hline
\end{tabular}

Fracionamento coloidal

Além dos processos de troca iônica e tratamento ácido, o beneficiamento das argilas pode incluir também a purificação do mineral por fracionamento coloidal sob gravidade, permitindo a retirada de impurezas insolúveis como feldspato, mica, quartzo e caulinita. ${ }^{19}$ Montmorilonitas com alto grau de pureza têm aplicação em uma grande variedade de áreas como adsorventes seletivos, medicamentos, membranas, produção de argilas organofílicas, catalisadores, entre outros. O processo de purificação por fracionamento coloidal não é realizado em escala industrial e representa uma oportunidade interessante para a obtenção de amostras de argilas com características bastante homogêneas em escala de laboratório. O grupo de Sarikaya ${ }^{20}$ investigou os materiais obtidos em um protocolo simples de sedimentação coloidal fracionada de bentonita. Os difratogramas de raios X da amostra de bentonita original (RT) e das frações obtidas em sedimentações sucessivas da suspensão de bentonita durante vários intervalos de tempo (F1 a F4) estão na Figura 6. Montmorilonita de alta pureza $(\mathrm{F} 4)$ foi obtida na última etapa do protocolo de fracionamento, com um rendimento de $50 \%$ em massa.

A associação dos processos de beneficiamento que foram descritos pode representar oportunidades interessantes para a obtenção de materiais de alta pureza, com características planejadas, para atender as demandas de mercado nacionais, tanto das indústrias quanto dos pesquisadores acadêmicos. Um protocolo de purificação e fracionamento incluindo a ativação ácida da argila bruta, para esfoliação das lamelas dos argilominerais, seguido do fracionamento coloidal das impurezas minerais e posterior neutralização da acidez da suspensão de argila com hidróxido de sódio pode, tecnicamente, ser desenvolvido em escala industrial para obtenção de argila sódica nacional com elevado padrão de pureza.

\section{MODIFICAÇ̃̃O QUÍMICA DE ARGILAS}

A modificação química das argilas permite o ajuste de suas propriedades físico-químicas, agregando funcionalidades aos materiais para uso em diversos tipos de aplicações tecnológicas. ${ }^{21} \mathrm{O}$ conceito de modificação química que será abordado neste artigo é o da modificação das superfícies das lamelas individuais de argila que, empilhadas, compõem os grãos do mineral. Quando a modificação é feita apenas na superfície dos grãos, as argilas têm aplicações nas quais é adicionada como carga micrométrica na composição de materiais. ${ }^{22}$ Serão discutidos dois tipos de modificação química: a organofilização das argilas, que torna as superfícies das lamelas hidrofóbicas, e a pilarização, onde o ajuste da distância interlamelar é feito pela intercalação de cátions inorgânicos de diferentes tamanhos.

As argilas esmectitas são caracterizadas por sua capacidade de 


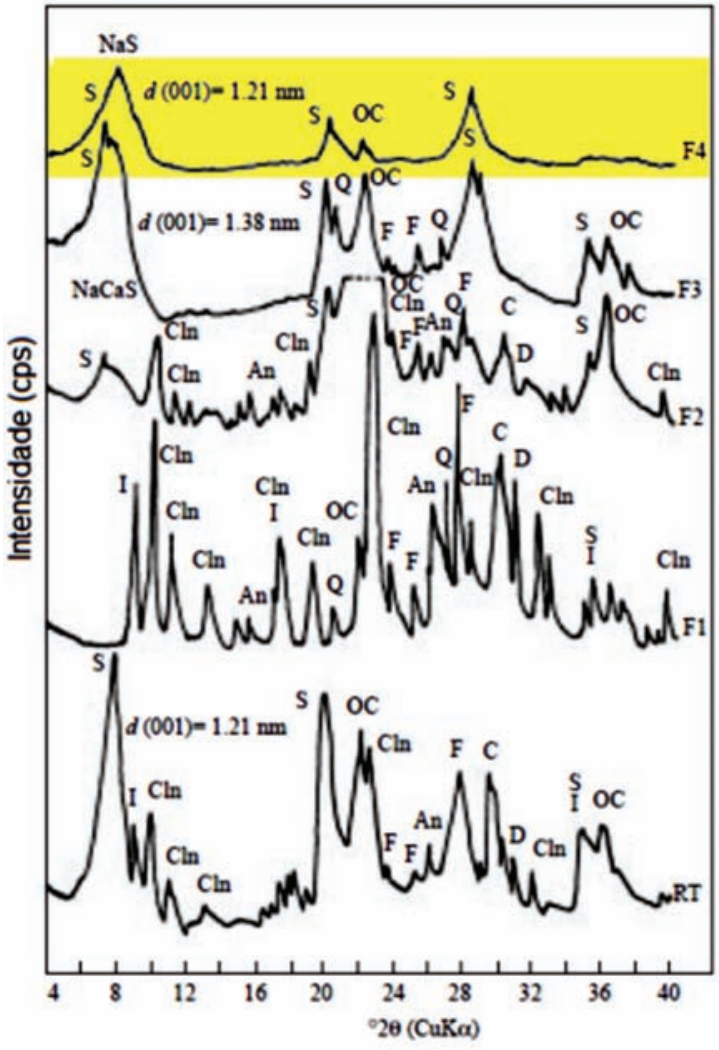

Figura 6. Difratogramas de raios $X$ da bentonita original e de suas fraç̃es (An = analcima,$C=$ calcita, $C l n=$ clinoptilolita,$D=$ dolomita,$F=$ feldspato, $I=$ ilita,$O C=$ opala-C, $Q=$ quartzo, $S=$ esmectita). Adaptada da ref. 20. $O$ difratograma da fração de bentonita de alta pureza (F4), obtida na última etapa do protocolo de fracionamento, está destacado em amarelo

troca de cátions (CTC), ${ }^{23}$ que quantifica o número de cátions interlamelares trocáveis em um processo de modificação química por cátions orgânicos ou inorgânicos. O termo argilas catiônicas é usado para designar tanto as argilas sódicas como as cálcicas.

\section{Organofilização}

As argilas organofílicas são obtidas pela troca iônica dos cátions interlamelares de argilas catiônicas por cátions orgânicos, principalmente tensoativos quaternários de amônio. Dessa forma, a superfície das lamelas individuais de argila torna-se hidrofóbica. A hidrofobização das lamelas também pode ser obtida pela adsorção de tensoativos não-iônicos etoxilados sobre suas superfícies, via interação eletrostática com os cátions interlamelares. Processos e tensoativos alternativos para a fabricação de argilas organofílicas estão protegidos por patentes no Brasil. ${ }^{24}$

As argilas organofílicas são matérias-primas de elevado valor agregado para uma série de aplicações industriais. A maior parte da argila organofílica adquirida no mercado nacional é importada. Sua produção industrial é pequena no Brasil, contando com a atuação de poucas empresas, como a Spectrochem Ind. e Com. de Aditivos Ltda., de Santa Catarina, que atualmente fornece argilas organofílicas para os mercados de tintas, graxas e resinas de poliéster. Assim, o desenvolvimento tecnológico da fabricação de argilas organofílicas ${ }^{25}$ em escala industrial é economicamente interessante para o Brasil.

Os protocolos de organofilização descritos na literatura científica geralmente envolvem a preparação de suspensões aquosas de argila, com concentrações entre 3 e $10 \%$ em massa, e a posterior adição de soluções de tensoativos quaternários de amônio à suspensão. ${ }^{26} \mathrm{~A}$ argila organofílica assim obtida forma uma torta úmida, que é separada por filtração, seca em estufa e moída. Esse modelo de protocolo, apesar de possibilitar a obtenção de argilas organofílicas de excelente qualidade, não é economicamente viável em escala industrial devido ao custo muito elevado envolvido no processo de secagem da torta úmida. Dessa forma, o desenvolvimento tecnológico de protocolos de organofilização de argilas que eliminem a etapa de dispersão da argila in natura em água é essencial para a diminuição dos custos de produção desse importante insumo industrial.

\section{Pilarização}

O processo conhecido como pilarização de argilas é um método bastante usado em catálise heterogênea. ${ }^{27}$ É necessário que o material de partida seja uma esmectita, que possui propriedades de inchamento e troca iônica, essenciais para esse processo. Argilas pilarizadas são materiais com estruturas abertas e rígidas obtidas pela intercalação de espécies volumosas nos espaços interlamelares. Elas possuem geralmente altas áreas superficiais $\left(50\right.$ a $\left.200 \mathrm{~m}^{2} \mathrm{~g}^{-1}\right)$, grandes volumes de poro e tamanhos de poro ajustáveis, além de fornecerem acidez superficial forte e pilares de óxidos metálicos cataliticamente ativos. As argilas pilarizadas são catalisadores hidrotermicamente menos estáveis que as zeólitas, mas podem possuir poros maiores, favorecendo reações de moléculas mais volumosas.

O processo de preparação de uma argila pilarizada está resumido nos seguintes passos: inchamento da esmectita com água; troca dos cátions interlamelares por complexos metálicos oligoméricos ou poliméricos parcialmente hidratados; secagem e calcinação para transformação dos precursores polioxocátions em pilares de óxido metálico. ${ }^{27}$ Nessa última etapa os pilares óxidos se ligam covalentemente às folhas tetraédricas da argila, mantendo-as separadas permanentemente.

Os polioxocátions, que também podem ser chamados de agentes pilarizantes, são comumente constituídos por complexos de metais como alumínio, cromo, ferro, titânio e zircônio. ${ }^{27}$ Os pilares podem ser constituídos por uma única espécie de óxido metálico ou por combinação de dois ou mais óxidos. Um diagrama que esquematiza um dos tipos mais comuns de pilarização de argilas do tipo esmectita, com pilares de alumina, pode ser visto na Figura $7 .{ }^{28} \mathrm{O}$ agente pilarizante usado é um cluster de alumínio (íon de Keggin) que, após o processo de calcinação, é transformado em óxido de alumínio, com a liberação de $\mathrm{H}^{+}$e água.

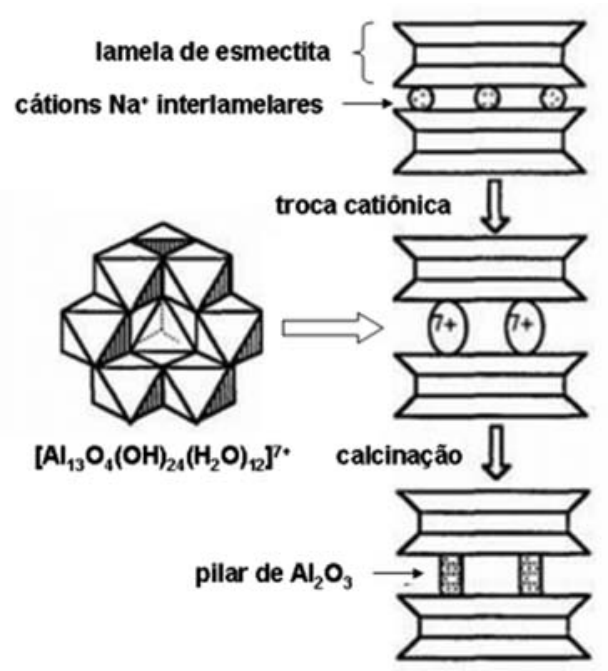

Figura 7. Diagrama esquemático da pilarização de uma esmectita com alumina. Adaptada da ref. 28 
A acidez das argilas pilarizadas é um fator muito importante a ser considerado para a sua aplicação catalítica e, portanto, tanto a escolha da argila de partida quanto a do tipo de pilar a ser preparado devem ser levados em conta a depender do tipo de reação em que o catalisador será usado. ${ }^{27} \mathrm{~A}$ acidez de Brønsted provem principalmente das substituições de $\mathrm{Si}^{4+}$ por $\mathrm{Al}^{3+}$ nas folhas tetraédricas, que é mais extensa nas saponitas do que nas montmorilonitas, por exemplo. Já a acidez de Lewis é proveniente do pilar de óxido metálico. Além disso, é possível aumentar a acidez dos materiais realizando-se um processo de ativação ácida (como descrito anteriormente) antes do processo de pilarização.

\section{APLICAÇÕES DE ARGILAS QUIMICAMENTE MODIFICADAS}

O número de patentes protegendo aplicações de argilas quimicamente modificadas para a fabricação de produtos no Brasil, que foram identificadas nas pesquisas realizadas para a redação deste artigo, é de 150. As argilas modificadas são usadas em diversas aplicações tecnológicas, desde a formulação de tintas e graxas até a fabricação de sistemas de liberação controlada de fármacos. Serão apresentadas as aplicações mais relevantes de argilas modificadas para a fabricação de produtos comerciáveis.

\section{Fluido de perfuração base óleo}

Argilas organofílicas são usadas como agente disperso na composição dos fluidos de perfuração base óleo, ${ }^{29}$ desempenhando funções importantes durante a perfuração, como de sustentação mecânica das paredes do poço, contenção da produção indesejável de fluidos presentes na formação, lubrificação e resfriamento da broca e, principalmente, transporte dos detritos perfurados até a superfície. Os fluidos de perfuração base óleo foram desenvolvidos para perfurações de formações constituídas de rochas ativas, bem como em perfurações sob condições de altas temperaturas e pressões, em poços profundos e direcionais, muito frequentes em exploração offshore. ${ }^{25}$ Há 21 patentes depositadas no Brasil protegendo o uso de argilas organofílicas para a formulação de fluidos de perfuração base óleo. Em nenhum dos casos o depositante é uma empresa brasileira.

\section{Nanocompósitos polímero-argila}

A esfoliação homogênea de baixas frações mássicas $(0,2$ a $10 \%$ ) de lamelas de argila dentro de matrizes poliméricas modifica as propriedades mecânicas, térmicas e de barreira a gases dos polímeros, resultando em materiais com propriedades melhoradas para diversas aplicações, mantendo boas propriedades óticas (evitando a opacificação dos materiais). ${ }^{30}$ A esfoliação de lamelas de argilas dentro de matrizes poliméricas é facilitada pela sua organofilização, que promove melhoras na compatibilização entre as fases das lamelas inorgânicas de argila e a matriz polimérica orgânica.

No Brasil há 45 depósitos de patente protegendo processos e formulações para a fabricação de materiais nanocompósitos de polímeroargila usando argilas organofílicas em sua formulação. Desse total, 31 depósitos foram feitos por empresas estrangeiras, 7 por empresas brasileiras, 3 por universidades estrangeiras e 4 por universidades nacionais. Apesar disso, nas pesquisas que realizamos não foram identificados nanocompósitos poliméricos, preparados usando argilas organofílicas, sendo comercializados no mercado brasileiro.

Os principais processos para fabricação de nanocompósitos polímero-argila organofílica protegidos por patentes são: intercalação no estado fundido, polimerização in situ e solubilização/mistura do polímero com argila organofílica. ${ }^{31} \mathrm{O}$ processo de intercalação no estado fundido é o mais investigado para aplicação industrial, devido à sua viabilidade econômica. Entretanto, esse processo é realizado em temperaturas que levam à degradação térmica dos tensoativos modificadores de argilas mais comuns, os alquil quaternários de amônio. ${ }^{32}$ Muitos tipos de tensoativos diferentes já foram investigados para a obtenção de argilas organofílicas com maior estabilidade térmica. Uma oportunidade interessante para a obtenção de argilas organofílicas resistentes à degradação térmica, nas temperaturas de fabricação dos nanocompósitos, é sua fabricação usando tensoativos alquil etoxilados. ${ }^{24}$

\section{Agroquímicos}

As patentes depositadas no Brasil protegendo o uso de argilas para a formulação de produtos agroquímicos descrevem a obtenção de composições agroquímicas inseticidas, praguicidas, bactericidas e fungicidas. ${ }^{33}$ Os ativos agroquímicos são geralmente moléculas orgânicas com grupos polares e solubilidade limitada em água. O uso de argilas, organofílicas ou catiônicas, nas formulações permite a adsorção dos ativos agroquímicos nos espaços entre suas lamelas, melhorando a estabilidade química das moléculas ativas e proporcionando controle sobre a cinética de sua liberação durante a aplicação.

Os artigos de um número especial da revista Applied Clay Science discutiram em detalhes a diversidade de interações possíveis entre pesticidas e argilas. ${ }^{34}$ Algumas moléculas de pesticidas são catiônicas e podem ser intercaladas por um processo de troca catiônica. Outras possuem grupos funcionais polares $\left(-\mathrm{OH},=\mathrm{O},-\mathrm{Cl},-\mathrm{NO}_{2}\right)$ e interagem via forças eletrostáticas (íon-dipolo) em argilas trocadas com cátions específicos $\left(\mathrm{Fe}^{3+}\right.$, por exemplo). Alternativamente, moléculas de água podem servir como ponte entre esses cátions e o pesticida. Forças de van der Waals também podem ser responsáveis pelo processo de adsorção: pode-se utilizar uma argila organofílica (contendo geralmente íons alquil quaternários de amônio nos sítios de troca) como adsorvente para o pesticida - esse é o tipo de interação mais encontrado na literatura científica e de patentes.

O interesse em se produzir formulações pesticidas com liberação controlada para o ambiente motiva o uso de argilas como carreadoras de ativos agroquímicos. As argilas com cátions trocáveis da classe das esmectitas, como a montmorilonita, podem fazer o papel de carreadoras dessas espécies e, a depender da interação da molécula do agroquímico com a argila, o tempo de liberação pode ser ajustado. ${ }^{34}$

O processo de adsorção e dessorção da molécula herbicida neutra hexazinona em argilas catiônicas, trocadas com diferentes cátions, e em argilas organofílicas, modificadas com diferentes tensoativos, foi investigado para o desenvolvimento de sistemas de liberação controlada. ${ }^{35} \mathrm{O}$ grau de adsorção dessa molécula foi maior em montmorilonita catiônica trocada com íons $\mathrm{Fe}^{3+}$. Esse resultado foi atribuído à protonação do pesticida no espaço interlamelar da argila trocada com íons $\mathrm{Fe}^{3+}$, permitindo retenção da molécula no espaço interlamelar por um mecanismo de troca catiônica. ${ }^{34}$ Segundo os autores, o tipo de argila quimicamente modificada deve ser escolhido de acordo com a aplicação do material, já que cada argila apresenta diferentes cinéticas de liberação de ativos. Esse tipo de sistema também minimiza perdas de ativos por lixiviamento, prevenindo a diminuição de sua atividade pesticida e diminuindo os riscos de contaminação ambiental.

Uma abordagem para se obter argilas com altas concentrações de ativos agroquímicos é preparar emulsões do pesticida com tensoativos e, com as moléculas ativas solubilizadas em micelas, promover sua intercalação entre as lamelas de argilas catiônicas esfoliadas. ${ }^{36}$ Relata-se também o uso de vesículas como as de, por exemplo, fosfatidilcolina para o encapsulamento de espécies herbicidas para posterior intercalação na argila. ${ }^{37}$ Essa estratégia pode ser útil quando se trata de uma molécula aniônica. 
O uso excessivo de produtos agroquímicos, contaminando o ambiente e deixando resíduos em alimentos, tem sido noticiado recentemente no Brasil..$^{38}$ Dessa forma, há espaço para o desenvolvimento de novas alternativas de produtos que permitam maior controle na aplicação de pesticidas, com baixo custo e simples manuseio, incentivando os agricultores a empregá-los.

\section{Detergentes}

As argilas são usadas industrialmente como carreadoras de tensoativos para produtos detergentes de lavanderia. Há patentes brasileiras que protegem o uso de bentonitas para a formulação de produtos tensoativos que agridem menos a pele do usuário e que produzem melhor efeito visual em peças de vestuário. ${ }^{39}$ Além disso, as argilas podem atuar como carreadoras de perfume ou de substâncias antioxidantes para produtos de lavanderia. Os tensoativos, perfumes e antioxidantes são adsorvidos entre as lamelas de argilas organofílicas ou catiônicas e são liberados na sua aplicação. A liberação das moléculas pode ocorrer pela solubilização lenta em meio aquoso dos tensoativos intercalados ou pela ação mecânica sobre a argila modificada durante o processo de lavagem, causando a esfoliação dos grãos de argila e a liberação das moléculas.

Na literatura científica não há muitos estudos sobre a liberação de tensoativos intercalados em argila para uso em detergentes. Há trabalhos que investigam a adsorção de compostos orgânicos aromáticos, que são contaminantes ambientais, ${ }^{40} \mathrm{em}$ argilas organofílicas intercaladas com diferentes tensoativos, para remediação de solos. Não foram, porém, encontrados trabalhos investigando o lixiviamento de tensoativos de argilas organofílicas em meio aquoso, o que pode ser de interesse tanto para as indústrias de tensoativos como para as que utilizam argilas organofílicas como carreadoras de substâncias para liberação controlada (como no caso dos pesticidas, citados na seção anterior).

\section{Fármacos}

Existem muitos produtos farmacêuticos no mercado que incluem argilas como excipientes em suas formulações, por exemplo, Mebendazol, Bac-Sulfitrin, Pipurol ${ }^{\circledR}$, Deltaflan, Calferon e Nimesulon. Há exemplos de patentes depositadas no Brasil protegendo a fabricação de medicamentos oftálmicos e adesivos dérmicos nos quais as argilas são aplicadas como carreadoras do princípio ativo. ${ }^{41}$

É importante lembrar que existem alguns requisitos importantes para que uma argila seja usada em preparações farmacêuticas e cosméticas. ${ }^{42} \mathrm{Em}$ especial destacam-se a granulometria, o grau de pureza mineral, a quantidade de água adsorvida, composição química e contaminação microbiológica. Dentre os filossilicatos, apenas a caulinita, o talco, as esmectitas e as argilas fibrosas são utilizados em aplicações farmacêuticas e/ou cosméticas. No caso de administrações tópicas, minerais como o talco e a caulinita podem carregar fármacos (antibióticos, analgésicos, anti-histamínicos) adsorvidos superficialmente, que são liberados quando em contato com a pele úmida. ${ }^{43}$ As argilas esmectitas possuem altas capacidades de troca catiônica e podem ser usadas para a intercalação de moléculas orgânicas com ou sem grupos polares. ${ }^{42}$ As argilas modificadas são usadas para administração oral de fórmulas com liberação controlada. Algumas empresas comercializam esmectitas de grau farmacêutico como, por exemplo, as argilas Veegum ${ }^{\circledR}$ e a Polargel ${ }^{\circledR}$, que passam por um processo de lavagem em água. ${ }^{44}$

Embora muitos trabalhos relatem a preparação de híbridos a partir de argilas organofílicas ${ }^{45}$ ou a partir de nanocompósitos polímeroargila, ${ }^{46}$ nos ateremos aqui ao caso específico da intercalação direta dos fármacos nas argilas. Nesse caso, as moléculas de interesse são imobilizadas entre as lamelas por um processo de troca catiônica. Para que isso ocorra é necessário que a droga em questão esteja em sua forma básica. Em função do tamanho e da basicidade das moléculas do fármaco, diferentes tipos de interação com a argila podem ocorrer, alterando assim sua cinética de liberação. ${ }^{47}$

A liberação controlada do fármaco, promovida pela sua interação com a argila, permite controle na sua administração, mantendo níveis constantes de concentração no sangue por tempo longo. ${ }^{48}$ Esse fenômeno pode ser benéfico quando a dessorção lenta e controlada da droga tem um efeito positivo na ação terapêutica do medicamento, que é o caso de, por exemplo, anfetaminas e antibióticos. A liberação da droga também pode ser planejada para ocorrer apenas em ambientes químicos alvos após sua administração oral, como quando em contato com fluido intestinal, onde há aumento da força iônica do meio.

Na maioria dos trabalhos sobre o uso de argilas em sistemas de liberação controlada, observa-se uma melhora na solubilidade do fármaco no seu ambiente de aplicação alvo. Fármacos como sertralina, ${ }^{49}$ itraconazol, ciclosporina e carvedilol ${ }^{50}$ são cristalinos nas suas formas sólidas puras e, quando imobilizados na argila, são amorfos. Além disso, observa-se que há uma liberação rápida referente às moléculas adsorvidas na superfície, seguida de uma liberação lenta e contínua, relativa às moléculas presentes na região interlamelar. ${ }^{50}$ Podem ocorrer também mudanças conformacionais nas moléculas devido ao confinamento. ${ }^{51}$ Moléculas de elevada toxicidade, a exemplo do 5-fluorouracil, podem ser mais bem toleradas quando intercaladas, por terem liberação mais lenta no organismo. ${ }^{52}$

Alguns desafios tecnológicos para a fabricação das argilas carregadas com fármacos estão ligados principalmente à necessidade do uso de solventes orgânicos para a intercalação de substâncias pouco solúveis em água. Essas substâncias são as mais interessantes para sistemas de liberação, já que pode haver ganhos na biodisponibilidade do fármaco intercalado. ${ }^{50}$ Outra questão tecnológica está relacionada à não liberação de parte das moléculas, que ficam fortemente adsorvidas na superfície da argila. Isso pode causar a necessidade de intercalação de excesso do fármaco para obtenção de um medicamento com desempenho adequado. ${ }^{49}$ É importante notar que a maioria dos trabalhos que relatam sistemas de liberação argila-fármaco não usa argilas de grau farmacêutico. Desse modo, seria importante realizar estudos de liberação in vitro e in vivo dessas moléculas em argilas farmacêuticas comerciais.

Além de fármacos, é possível usar também as argilas como matrizes para sistemas de liberação de suplementos alimentares, tais como os antioxidantes. Podem ser usados inclusive produtos naturais como, por exemplo, o açaí, uma fruta rica em moléculas de antocianinas, que são antioxidantes. ${ }^{53}$ Intercaladas, essas moléculas ganham estabilidade térmica e podem resistir a um maior tempo de estocagem.

\section{Cosméticos}

Os principais usos de argilas na indústria de cosméticos são para o ajuste de propriedades reológicas e para estabilizar emulsões e suspensões. ${ }^{54}$ Quando fazem parte de uma formulação industrial cosmética, que em geral inclui moléculas tensoativas, perfumes, antioxidantes, dentre outras, espera-se que as argilas sofram algum tipo de modificação química - principalmente quando se trata de um produto líquido ou pastoso, nos quais as argilas estão em suspensão. Bentonitas são usadas para estabilizar emulsões óleo em água em produtos cremosos. Sua função é permanecer entre as duas fases da emulsão como um protetor. As argilas são usadas como agentes reológicos nesse tipo de emulsão, principalmente porque podem ser molhadas por ambas as fases líquidas. Elas agem, desse modo, como uma barreira física que previne a coalescência das gotas de líquido da emulsão, impedindo a separação de fases..$^{54}$ 
Há produtos cosméticos industriais, que usam argilas, patenteados no Brasil para usos como cuidados com a pele e cabelos. ${ }^{55}$ Além de serem usadas in natura, as argilas podem sofrer modificações antes de serem aplicadas em alguma formulação específica, podendo inclusive funcionar como agentes de liberação de substâncias específicas, como hidratantes, por exemplo. ${ }^{56}$

Os requisitos que as argilas devem possuir para serem usadas em cosméticos são os mesmos listados na seção anterior, sobre produtos farmacêuticos.

\section{Catalisadores}

Existem inúmeras aplicações industriais de catalisadores baseados em argilas. Alguns exemplos de produtos e processos usando argilas que estão protegidos por patentes no Brasil incluem catalisadores para redução do nitrogênio de espécies $\mathrm{NO}_{\mathrm{x}}$ (indústria automotiva), isomerização de alfa-olefinas, suporte para catalisador baseado em zeólitas, produção de argila pilarizada e isomerização de lactonas ${ }^{57}$ As aplicações industriais mais promissoras de argilas como catalisadores são na área de química orgânica e/ou química fina. Os catalisadores baseados em argilas apresentam características importantes, como facilidade na reutilização e recuperação, condições experimentais de operação brandas, ganhos em seletividade e conversão etc.

Praticamente todos os trabalhos de catálise que usam argilas empregam argilas tratadas com ácido e/ou pilarizadas. O tratamento ácido possibilita a obtenção de altas áreas superficiais, maior porosidade e alta acidez superficial. As melhores condições de acidez e de atividade catalítica são comumente obtidas quando as argilas são submetidas a tratamentos ácidos brandos. A atividade de uma montmorilonita tratada com ácido para a benzilação de compostos aromáticos, por exemplo, aumenta até um ponto máximo e depois diminui, com o aumento da concentração do ácido usado para o tratamento do catalisador de argila. ${ }^{58}$

No Brasil, alguns grupos de pesquisa usam argilas tratadas com ácido e/ou pilarizadas para catálise. Há relatos de estudos envolvendo a preparação e o uso de argilas pilarizadas com alumínio, nióbio, térbio e cromo, por exemplo. ${ }^{59}$ Há ainda estudos que utilizam argilas nacionais como a Brasgel (bentonita sódica ativada comercializada pela Bentonit União Nordeste Ind. e Com. Ltda), mas há uma falta de dados comparativos entre o uso das argilas brasileiras e das similares importadas. ${ }^{60}$

\section{CONCLUSÕES}

As argilas são recursos naturais que têm propriedades físicoquímicas ajustáveis, possibilitando seu uso na fabricação de diversos tipos de produtos, que demandam características específicas do material. A modificação química da superfície das lamelas individuais das argilas pode ser conseguida em processos de troca catiônica, com a obtenção de materiais hidrofílicos ou hidrofóbicos, que têm características estruturais controladas. É estratégico para o Brasil, como detentor de uma das maiores reservas mundiais de argila, fomentar a criação de parcerias de pesquisa entre os setores acadêmico e industrial para o desenvolvimento de novas tecnologias de obtenção de produtos formulados com argilas quimicamente modificadas, visando a agregação de valor a esse importante recurso natural.

\section{AGRADECIMENTOS}

Aos grupos dos Profs. H. C. Ferreira (DEMA-UFCG), F. Galembeck (IQ-UNICAMP) e V. R. L. Constantino (IQ-USP) e ao Centro de Tecnologia da Oxiteno pela experiência compartilhada sobre o tema. A. A. Teixeira-Neto agradece também à CAPES pela bolsa Prodoc concedida.

\section{REFERÊNCIAS}

1. Bergaya, F.; Theng, B. K. G.; Lagaly, G., eds.; Handbook of Clay Science, Elsevier: Amsterdam, 2006.

2. http://www.capes.gov.br/servicos/sala-de-imprensa/36-noticias/1990, acessada em Janeiro 2009.

3. Souza Santos, P.; Ciência e Tecnologia de Argilas, $2^{\mathrm{a}}$ ed., Edgar Blücher: São Paulo, 1992, vol. 1.

4. Baltar, C. A. M.; da Luz, A. B., eds.; Insumos Minerais para Perfuração de Poços de Petróleo, Centro de Tecnologia Mineral: Recife, 2003.

5. Foletto, E. L.; Volzone, C.; Morgado, A. F.; Porto, L. M.; Resumos do IV Coloquio Latinoamericano de Fractura y Fatiga, Neuquém, Argentina, 2000.

6. Velde, B.; Introduction to Clay Minerals, Chapman \& Hall: New York, 1992; Yariv, S.; Cross, H., eds.; Organo-Clay Complexes and Interactions, Marcel-Dekker: New York, 2002; Meunier, A.; Clays, Springer: Berlin, 2005.

7. Fahrenholtz, W. G. Em Ceramic and Glass Materials. Structure, Properties and Processing; Shackelford, J. F.; Doremus, R. H., eds.; Springer: New York, 2008, cap. 7.

8. Valenzuela-Díaz, F. R.; Souza Santos, P.; Quim. Nova 2001, 24, 345.

9. Moll Jr, W. F; Clays Clay Miner. 2001, 49, 374.

10. http://www.dnpm.gov.br/assets/galeriaDocumento/SumarioMineral2008/Bentonita.pdf, acessada em Janeiro 2008; da Luz, A. B.; de Oliveira, C. H. Em Rochas \& Minerais Industriais: Usos e Especificações; da Luz, A. B.; de Oliveira, C. H., eds.; Centro de Tecnologia Mineral: Rio de Janeiro, 2005, cap. 10.

11. Alves, T. S.; Zanini, A. E.; de Carvalho, L. H.; Cezário, M. V.; Resumos do $18^{\circ}$ CBECiMat, Porto de Galinhas, Brasil, 2008.

12. Hynes, R. E.; Nebergall, R. S.; Br PI 9.400.364-5, 1994.

13. Taylor, R. S.; Davies, M. E.; Turner, P. J.; Br PI 9.205.682-2, 1992.

14. Fayolle, D.; Br PI 0.515.333-6, 2005.

15. Rodrigues, M. G. F.; Pereira, K. R. O.; Valenzuela-Díaz, F. R.; Cerâmica 2006, 52, 260.

16. Bhattacharyya, K. G.; Gupta, S. S.; Adv. Colloid Int. Sci. 2008, 140, 114.

17. Önal, M.; Sarikaya, Y.; Powder Technol. 2007, 172, 14; Noyan, H.; Önal, M.; Sarikaya, Y.; Food Chem. 2007, 105, 156.

18. Bisio, C.; Gatti, G.; Boccaleri, E.; Marchese, L.; Langmuir 2008, 24, 2808.

19. Ferreira, H. S.; Dissertação de Mestrado, Universidade Federal de Campina Grande, Brasil, 2005.

20. Önal, M.; Sarikaya, Y.; Alemdaroğlu, T.; Bozdoğan, I.; Turk. J. Chem. 2003, 27, 683.

21. Coelho, A. C. V.; Souza Santos, P.; Souza Santos, H.; Quim. Nova 2007, 30,1282 .

22. Burmeister, N. M.; Br PI 9.701.731-0, 1997; Galembeck, F.; Br PI 9.301.191-1, 1993

23. Borden, D.; Giese, R. F.; Clays Clay Miner. 2001, 49, 444; Ammann, L.; Bergaya, F.; Lagaly, G.; Clay Miner. 2005, 40, 441; Vazquez, A.; Lopez, M.; Kortaberria, G.; Martin, L.; Mondragon, I.; Appl. Clay Sci. 2008, $40,24$.

24. Teixeira Neto, E.; Kuniyoshi, P.; Silva, A. L. C.; Calmanovici, C.; Br PI 0605519-2, 2006; Lagerman, R. K.; Br PI 9.200.670-1, 1992; Mardis, W. S.; Finlayson, C. M.; Br PI 8.202.246-1, 1982

25. Ferreira, H. S.; Martins, A. B.; da Costa, D. L.; Ferreira, H. C.; Neves, G. A.; de Melo, T. J. A.; Teixeira Neto, E.; Livro de Resumos Rio Oil \& Gas 2008 Expo and Conference, Rio de Janeiro, Brasil, 2008.

26. Meier, L. P.; Nueesch, R.; Madsen, F. T.; J. Colloid Int. Sci. 2001, 238, 24; Ferreira, H. S.; Martins, A. B.; da Costa, D. L.; Ferreira, H. C.; Neves, G. A.; de Melo, T. J. A.; Teixeira Neto, E.; Livro de Resumos Rio Oil \& Gas 2008 Expo and Conference, Rio de Janeiro, Brasil, 2008 . 
27. Kloprogge, J. T.; J. Porous Mater. 1998, 5, 5; Ding, Z.; Kloprogge, J. T.; Frost, R. L.; Lu, G. Q.; Zhu, H. Y.; J. Porous Mater. 2001, 8, 273; Vaccari, A.; Appl. Clay Sci. 1999, 14, 161; Luna, F. J.; Schuchardt, U.; Quim. Nova 1999, 22, 104; Pergher, S. B. C.; Corma, A.; Fornes, V.; Quim. Nova 1999, 22, 693.

28. Moore, D. M.; Reynolds, R. C.; X-ray Diffraction and the Identification and Analysis of Clay Minerals, $2^{\text {nd }}$ ed., Oxford University Press: New York, 1997.

29. Quintero, L.; J. Dispersion Sci. Technol. 2002, 23, 393; Jones, T. G. J.; Hughes, T. L.; Suspensions: Fundamentals and Applications in the Petroleum Industry, American Chemical Society: Washington, 1996.

30. Ray, S. S.; Okamoto, M.; Prog. Polym. Sci. 2003, 28, 1539.

31. Manias, E.; Touny, A.; Wu, L.; Strawhecker, K.; Lu, B.; Chung, T. C.; Chem. Mater. 2001, 13, 3516; LeBaron, P. C.; Wang, Z.; Pinnavaia, T. J.; Appl. Clay Sci. 1999, 15, 11

32. Xie, W.; Gao, Z. M.; Pan, W. P.; Hunter, D.; Singh, A.; Vaia, R.; Chem. Mater. 2001, 13, 2979; Gilman, J. W.; Appl. Clay Sci. 1999, 15, 31.

33. Okauchi, T.; Gotou, Y.; Sawamura, M.; Br PI 9105629-2, 1991; Matsunaga, T.; Abe, Y.; Kato, C.; Tanaka, Y.; Br PI 9.205.142-1, 1992; Braga, M.; Br PI 0.604.545-6, 2006; Lefiles, J. H.; Taylor, E. J.; Crawford, M. A.; Br PI 9.104.147-3, 1991.

34. Lagaly, G.; Appl. Clay Sci. 2001, 18, 205.

35. Celis, R.; Hermosin, M. C.; Carrizosa, M. J.; Cornejo, J.; J. Agric. Food Chem. 2002, 50, 2324.

36. Ziv, D.; Mishael, Y. G.; J. Agric. Food Chem. 2008, 56, 9159.

37. Sanchez-Verdejo, T.; Undabeytia, T.; Nir, S.; Villaverde, J.; Maqueda, C.; Morillo, E.; J. Agric. Food Chem. 2008, 56, 10192; Undabeytia, T.; Nir, S.; Gomara, M. J.; Langmuir 2004, 20, 6605.

38. http://www1.folha.uol.com.br/folha/ciencia/ult306u394971.shtml; http:// www1.folha.uol.com.br/folha/cotidiano/ult95u395147.shtml; acessadas em Janeiro 2009.

39. Hafkamp, R. J. H.; Menting, R.; Wierenga, A. M.; Br PI 0.213.135-8, 2002, Van Asten, A. C.; Van Doorn, D. A.; Wierenga, A. M.; $B r P I$ 0.214.602-9, 2002, Ouhadi, T.; Dehan, L.; Julemont, M.; Zocchi, G.; Mineo, M.; Fonsny, P.; Br PI 8.80.2948-4, 1988.

40. Gitipour, S.; Bowers, M. T.; Bodocsi, A.; J. Colloid Int. Sci. 1997, 196, 191.

41. Ketelson, H. A.; Meadows, D. L.; Br PI 0.215.149-9, 2002, Sablotsky, S.; Gentile, J. A.; Br PI 9.008.012-2, 1990

42. López-Galindo, A.; Viseras, C.; Cerezo, P.; Appl. Clay Sci. 2007, 36 , 51.
43. Carretero, M. I.; Appl. Clay Sci. 2002, 21, 155

44. http://www.rtvanderbilt.com/spec_pc_1.htm; http://www.healthbeautysolutions.com/Polargel.asp; acessadas em Janeiro 2009.

45. Lee, W. F.; Fu, Y. T.; J. Appl. Polym. Sci. 2003, 89, 3652

46. Craig, D. Q. M.; Mc Nally, ??; US pat. 0.147.538, 2006

47. Aguzzi, C.; Cerezo, P.; Viseras, C.; Caramella, C.; Appl. Clay Sci. 2007, $36,22$.

48. Carretero, M. I.; Appl. Clay Sci. 2002, 21, 155.

49. Nunes, C. D.; Vaz, P. D.; Fernandes, A. C.; Ferreira, P.; Romão, C. C.; Calhorda, M. J.; Eur. J. Pharm. Biopharm. 2007, 66, 357.

50. Park, T.; Jung, H.; Kim, H. M.; Choy, J. H.; Lee, C. W.; US pat. $0.013 .877,2006$

51. Parolo, M. E.; Savini, M. C.; Vallés, J. M.; Baschini, M. T.; Avena, M J.; Appl. Clay Sci. 2008, 40, 179.

52. Lin, F. H.; Lee, Y. H.; Jian, C. H.; Wong, J.; Shieh, M.; Wang, C.; Biomater. 2002, 23, 1981

53. Teixeira Neto, A. A.; Izumi, C. M. S., Temperini, M. L. A.; Ferreira, A. M. C.; Constantino, V. R. L.; submetido.

54. Viseras, C.; Aguzzi, C.; Cerezo, P.; Lopez-Galindo, A.; Appl. Clay Sci. 2007, 36, 37 .

55. McCulloch, L.; Hopkins, J.; Br PI 0.204.573-7, 2001, Arai, T.; Baker, M. E. J.; Giles, C. C. D.; Br PI 0.214.263-5, 2002

56. Dias, P. M.; Br PI 0.604.286-4, 2006.

57. Hubig, S.; Kesore, K.; Mönnig, R.; Oswald, H.; Zima, P.; Br PI 0.508.901-8, 2005; Zhang, J. J.; Br PI 0.517.310-8, 2005; Costa, A. F.; Ferreira, J. M. F.; Lau, L. Y.; Almeida, M. B. B.; Br PI 0.503.784-0, 2005; Pellet, R. J.; Peter, F.; Rabo, J. A.; McCauley, J. R.; Miller, J.G.; Br PI 8.805.853-0, 1988; Shveima, J. S.; Br PI 9.204.298-8, 1992; Denis, P.; Metz, F.; Gilbert, L.; Grosselin, J.; Br PI 9.307.159-0, 1993.

58. Pushpaletha, P.; Rugmini, S.; Lalithambika, M.; Appl. Clay Sci., 2005, $30,141$.

59. Gallo, J. M. R.; Teixeira, S.; Schuchardt, U.; Appl. Catal., A 2006, 311 , 199; Melo, D. M. A.; Ruiz, J. A. C.; Melo, M. A. F.; Sobrinho, E. V.; Schmall, M.; Microporous Mesoporous Mater. 2000, 38, 345; Carvalho, W. A.; Eclética Química 2002, 27, 353; Oliveira, L. C. A.; Lago, R. M.; Fabris, J. D.; Sapag, K.; Appl. Clay Sci. 2008, 39, 218.

60. Villegas, R. A. S.; Santo, J. L. D.; de Mattos, M. C. S.; de Aguiar, M.; Guarino, A. W. S.; J. Braz. Chem. Soc. 2005, 16, 565; Correa, K. S. M.; Bernini, R. B.; de Mattos, M. C. S.; de Aguiar, M.; Guarino, A. W. S.; J. Braz. Chem. Soc. 2007, 18, 1509. 